\title{
ATUALIZAÇÃO EM FRATURA TRANSTROCANTERIANA
}

Autoria: Roberto Sérgio de Tavares Canto, Marcos Sakaki, Itiro Susuki, Pedro Tucci, Willian Belangero, Mauricio Kfuri Jr, Abdalla Y. Skaf, Wanderley Marques Bernardo

1) Qual a utilidade da tração cutânea ou esquelética no pré-operatório das fraturas transtrocantéricas?

a) Está indicada, pois reduz o consumo de analgésico

b) Está indicada, pois facilita o ato cirúrgico

c) Não é recomendada, pois aumenta a dor

d) Não é recomendada, pois não reduz o consumo de analgésico

e) Está indicada, pois reduz as escaras

2) qual o melhor procedimento anestésico para o paciente com fratura transtrocanteriana do fêmur?
a) $\mathrm{Na}$ anestesia espinal há menor tendência ao infarto do miocárdio
b) Não é recomendada a infusão epidural contínua de anestésico local
c) A recuperação funcional é maior no bloqueio do que na anestesia geral
d) A anestesia geral tem menor mortalidadea)
e) Na anestesia espinal há mais hipóxia

3) Existem vantagens no uso da placa medoff em relação ao dhs e às hastes cefalomedulares?
a) A placa Medoff não permite a dinamização biaxial
b) Não há igualdade em falha entre os diversos métodos
c) Nas fraturas subtrocantéricas há maior índice de falhas mecânicas
d) A dinamização biaxial não protege a osteossíntese
e) A haste Gamma produz maior índice de capacidade de deambulação

4) em fraturas transtrocanterianas instáveis, é melhor a fixação com redução anatômica ou com osteotomia e medialização?
a) A redução anatômica tem maior consolidação
b) A osteotomia demanda maior tempo de cirurgia
c) A osteotomia tem maior recuperação funcional
d) A redução anatômica tem maior tempo de hospitalização
e) As osteotomias estão indicadas

5) Quando e em quais condições o tratamento conservador ainda poderá ser adotado?

a) 0 repouso no leito não deve ser associado à mobilização precoce

b) Deve ser sempre adotado

c) As taxas de mortalidade são 2,5 vezes menores

d) 0 tratamento com tração apresenta maior mortalidade

e) 0 tratamento com tração esquelética reduz a consolidação viciosa

\section{Respostas ao Cenário Clínico: Entorse de tornozelo [Publicado na RAMB 2009; 55(5)]}

1) Como classificar a entorse de tornozelo? Em estiramento ligamentar, lesão ligamentar parcial e total (Alternativa D)

2) Em relação a radiografar pacientes com entorse é falso: A radiografia está sempre indicada (Alternativa $\mathrm{A}$ )

3) Está entre as medidas de tratamento inicial da entorse de tornozelo, exceto: Aplicação de calor local (Alternativa C)

4) É verdade sobre as possíveis complicações da entorse de tornozelo: $A$ instabilidade crônica é a lesão associada mais frequente (Alternativa B)

5) Qual a conduta a ser adotada nas instabilidades crônicas? Os pacientes com frouxidão ligamentar devem ser submetidos à reabilitação (Alternativa D) 